Research Article

\title{
Drug pattern use during pregnancy: a prospective study at tertiary care teaching hospital
}

\author{
Savitha A.*, Sarita H., Kashinath Gumma
}

Department of Pharmacology, BRIMS, Bidar, Karnataka, India

Received: 08 December 2015 Accepted: 07 January 2016

*Correspondence to:

Dr. Savitha A.,

Email: drsavitha96

@ rediffmail.com

Copyright: (C) the author(s), publisher and licensee Medip Academy. This is an openaccess article distributed under the terms of the Creative Commons Attribution NonCommercial License, which permits unrestricted noncommercial use, distribution, and reproduction in any medium, provided the original work is properly cited.

\begin{abstract}
Background: Pregnancy is a normal physiological state. It may be accompanied by some common conditions which may occur normally due to the physiological changes. For these, drug treatment may be necessary. Use of drug is of growing concern due to increased risk of teratogenicity. Hence use of safe drugs during pregnancy should be promoted. This study aims to study and evaluate the pattern of drug use in women attending the antenatal clinic.

Methods: A prospective cross sectional study was conducted in Obstetrics \& Gynecology out Patients department in BRIMS Teaching Hospital for a period of 3 months. All new antenatal cases reporting to outpatient department were included. Data were then analysed for drug use pattern, WHO core drug prescribing indicators and also according to FDA drug risk category and trimester wise drug use pattern.

Results: It was observed that most common complaint was epigastric distress. Iron, calcium and Antacids were the most frequently prescribed drugs. 79\% drugs were prescribed from essential drug list and $100 \%$ were given by generic name. Out of 3857 drugs prescribed $48.35 \%$ belonged to Cat A, 50.35\% to Cat $\mathrm{B}$ and only $1.3 \%$ to $\mathrm{Cat} \mathrm{C}$ and none of the drugs belonging to $\mathrm{Cat} \mathrm{D}$ were prescribed.

Conclusions: Overall drug use pattern is rational with few exceptions. Majority of the drugs prescribed are as per FDA category B. This type of study can help in evaluating the existing drug use pattern and in planning appropriate interventions to ensure rational drug therapy.
\end{abstract}

Keywords: Drug use pattern, Pregnancy, WHO core drug prescribing indicators

\section{INTRODUCTION}

Drugs play an important role in improving human health and promoting well-being. The state of pregnancy requires that all medications should be prescribed with specific caution. The physiological state of pregnancy has an effect on the pharmacokinetics of drugs administered, with attendant risk on the developing foetus. ${ }^{1}$ Therefore categorization of drugs according to their pregnancy risk should be taken into consideration before a drug is prescribed for pregnant women. However to produce the desired effect, they have to be safe, efficacious and have to be used rationally

Now there is a greater appreciation of the risks of drug use in pregnancy. It should be practiced that maternal pharmacotherapy should be avoided or minimized where possible. Approximately $2-3 \%$ of all live births are associated with a congenital anomaly. Although exogenous factors such as drugs may account for only 1 $5 \%$ of these (affecting less than $0.2 \%$ of all live births),given that drug associated malformation are largely preventable, they remain an important consideration. $^{2}$

The use of drugs in pregnancy is an issue of great concern to the patients and prescribers alike. The Thalidomide incidence of the 1960's and the teratogenic effects that was discovered related to Diethylstilboestrol in 1971 are a few instance of the dangers which prescription drugs may pose to pregnant subjects. ${ }^{1}$ Pregnancy is associated with changes in the physiological, psychological and psychosocial aspects of a woman's life. Drug pharmacokinetic parameters are usually affected by the type of drugs administered in pregnancy, most administered drug passes the placental 
barrier, and depending on the stage of pregnancy, the life of the foetus may be threatened. Therefore, special consideration needs to be given to drug prescribing in pregnancy. ${ }^{3}$ Safe use of drugs in pregnancy is a responsibility of all members of the healthcare team, nevertheless, the bulk of this responsibility rests on the Physicians shoulder.

In 1979, the Food and Drug Administration developed a system determining the teratogenic risk of drugs by considering the quality of data from animal and human studies. It provides therapeutic guidance for the clinician. Category A is considered the safest category but some drugs from categories B, C and D are also used during pregnancy. Category $\mathrm{X}$ is the only rating that denotes a drug is absolutely contraindicated for use during pregnancy. ${ }^{4}$ Categories are summarized as follows:

Category-A: Controlled studies in women fail to demonstrate a risk to the fetus in the first trimester, there is no evidence of a risk in later trimesters and the possibilities on the fetal harm appears remote.

Category-B: Either animal reproduction studies have not demonstrated a fetal risk but there are no controlled studies in pregnant women or animal reproductive studies have shown an adverse effect (other than a decrease in fertility) that was not confirmed in controlled studies in women in first trimester and there is no evidence of risk in later trimesters.

Category-C: Either studies in animals have revealed adverse effect on the fetus (teratogenic, embryological, or other) and there are no controlled studies in women and animals are not available. Drugs should be given only if the potential benefit justifies the potential risk to the fetus.

Category-D: There is positive evidence of human fetal risk, but the benefits from use in pregnant women may be acceptable despite the risk. (e.g., if the drug is needed in a life-threatening situation or a serious disease for which safer drugs cannot be used or are ineffective).

Category-X: Studies in animals or human beings have demonstrated fetal abnormalities or there is evidence of fetal risk based on human experience or both and the risk of the use of the drug in pregnant women clearly outweighs any possible benefit. The drug being contraindicated in women who are or may become pregnant. $^{5}$

\section{METHODS}

This prospective cross sectional study was carried out in obstetrics and Gynecology outpatient department of a tertiary care teaching hospital BRIMS, Bidar, India from April 2015 to June 2015. Only the new cases of antenatal patients were included. After taking verbal consent from women the data were collected in a pre-designed proforma which included patient's demographic details, pregnancy duration, chief complaints/ provisional diagnosis and complete prescription. Data were analyzed for demographic characteristics, drug use pattern, and percentage of drugs prescribed as fixed dose combination and WHO core drug prescribing indicators. ${ }^{6}$ Data were also analyzed according to FDA (Food and Drug Administration, USA) drug risk category and trimester wise drug use pattern. ${ }^{7}$ Results were expressed in percentage and MeanSD \pm 2 .

\section{RESULTS}

A total 1000 women received 3857 prescriptions. The age of patients ranged from 18-40 years. Majority of the patients in the study were in the age group 25-35 years $(78.2 \%)$, followed by $<25$ years $(20.6 \%)$ and $>35$ years $(1.2 \%)$ (Table 1). Majority of patients in the study were in second trimester of gestation $(52.5 \%)$ followed by third trimester $(28 \%)$ and least in first trimester $(19.5 \%)$.

Table 1: Age wise distribution of antenatal women $(\mathrm{N}=1000)$.

\begin{tabular}{|lll|}
\hline Age groups (years) & No. of patients & Percentage \\
\hline$<25$ & 206 & $20.6 \%$ \\
\hline $25-35$ & 782 & $78.2 \%$ \\
\hline$>35$ & 12 & $1.2 \%$ \\
\hline
\end{tabular}

Most common complaints of women coming to antenatal OPD were epigastric distress (22.4\%), abdominal pain (14.8\%) and vomiting (13.8\%) followed by fever (6.5\%), cough (1.4\%), urinary tract infection $(2.7 \%)$ and discharge per vagina $(2.6 \%)$. Majority of women were coming for routine antenatal check-ups. Number of drugs prescribed was observed to vary with each trimester. Majority of the drugs were given to the patients in $2^{\text {nd }}$ trimester, followed by $3^{\text {rd }}$ trimester, and minimum drugs were given to 1 st trimester patients (Table 2).

Table 2: No. of drugs prescribed.

\begin{tabular}{|lll|}
\hline Drugs & No. of drugs given & $\%$ of drugs given \\
\hline $1^{\text {st }}$ trimester & 502 & $13.02 \%$ \\
\hline $2^{\text {nd }}$ trimester & 2058 & $53.36 \%$ \\
\hline $3^{\text {rd }}$ trimester & 1297 & $33.62 \%$ \\
\hline Total & 3857 & $100 \%$ \\
\hline
\end{tabular}

Calcium gluconate $(80.5 \%)$, Iron salts $(67 \%)$, Ranitidine $(56 \%)$ were most frequently prescribed drug groups followed by paracetamol (48\%), antispasmodic drug $(36.2 \%)$, antimicrobial agents $(26 \%)$, folic acid $(19.5 \%)$, antiemetic drugs (19.5\%) and others.

Out of 3857 drugs prescribed, $48.35 \%$ were FDA drug risk category A which is the safest category described by FDA followed by $50.35 \%$ belonged to Category B, $1.3 \%$ to Category $\mathrm{C}$ and none of the drugs belonging to category D were prescribed (Table 4). 


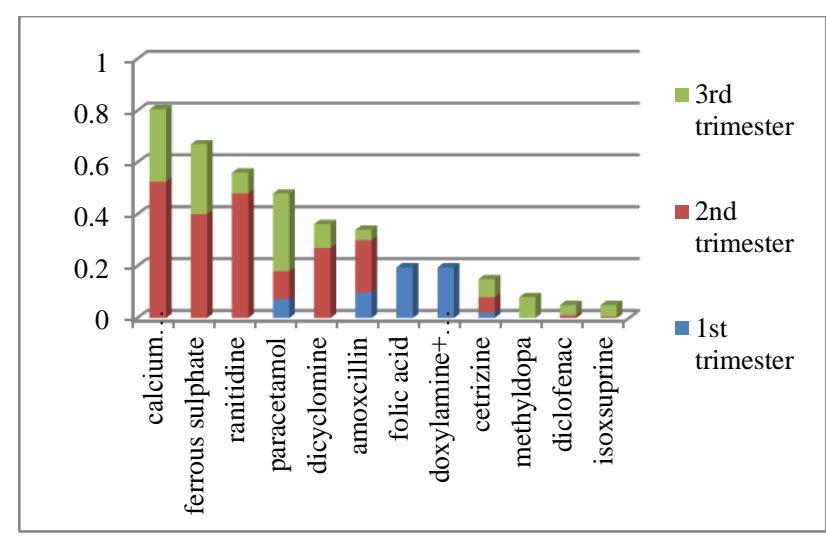

Figure 1: Prescribing frequency of different drugs $(n=1000)$.

Table 3: WHO core drug prescribing indicators.

\begin{tabular}{|ll|}
\hline Indicator & Value \\
\hline Average number of drugs per prescription & 3.85 \\
\hline $\begin{array}{l}\text { Percentage of drugs prescribed by generic } \\
\text { name }\end{array}$ & $100 \%$ \\
\hline $\begin{array}{l}\text { Percentage of encounters with antibiotic } \\
\text { prescribed }\end{array}$ & $26 \%$ \\
\hline $\begin{array}{l}\text { Percentage of encounters with an injection } \\
\text { prescribed }\end{array}$ & $1.29 \%$ \\
\hline $\begin{array}{l}\text { Percentage of drugs prescribed from } \\
\text { essential drug list }\end{array}$ & $79.08 \%$ \\
\hline $\begin{array}{l}\text { Percentage of Fixed dose combinations } \\
\text { prescribed }\end{array}$ & $5.05 \%$ \\
\hline
\end{tabular}

Table 4: FDA drug risk category wise prescription pattern.

\begin{tabular}{|ll|}
\hline Category & Percentage \\
\hline Category A & 48.35 \\
\hline Category B & 50.35 \\
\hline Category C & 1.3 \\
\hline Category D & 0 \\
\hline
\end{tabular}

\section{DISCUSSION}

Out of 1000 pregnant women, about $78.2 \%$ were between 25 to 35 years which represents the normal reproductive age group. About half of the patients visited antenatal OPD in second trimester. More than $50 \%$ of women in this study came for routine antenatal check-up, with no complaints. Calcium Iron and Antacids were the most frequently used drugs in pregnancy, accounting for $67 \%$, $80 \%$ and $56 \%$ respectively. Doxylamine and pyridoxine combination was used most commonly in first trimester followed by Paracetamol and Cetrizine acetate. Study from West Indies, multivitamins, iron/folic acid and calcium were the most frequently prescribed drugs during the first, second and third trimesters followed by dimenhydrinate, insulin, metformin and paracetamol. ${ }^{8}$
During second trimester Antacids followed by dicyclomine, paracetamol and in third trimester drug groups like uterine relaxants, analgesics, antimicrobial agents and antihypertensives were prescribed. In our study majority of drugs were from category B $(50.35 \%)$ followed by category A (48.35\%), category C $(1.3 \%)$ and category D $(0.00 \%)$. No drugs were prescribed from category $\mathrm{X}$. In a retrospective study in Finland, it was found that $20.4 \%$ of women purchased at least one drug classified as potentially harmful during pregnancy and $3.4 \%$ purchased at least one drug classified as clearly harmful. ${ }^{9}$ In a study by Bratislava and Nitra, it was reported that a vast majority of prescribed drugs during pregnancy, belonged to category $C{ }^{10}$ So from the above data we can say that the prescription habit in our set up was quite safe. Percentage of drugs prescribed by generic name was $100 \%$. Percentage of encounters with antibiotic prescribed was $26 \%$. Percentage of encounters with an injection prescribed was $5 \%$, which is also low. Percentage of drugs prescribed from essential drugs list was $79.08 \%$.

\section{ACKNOWLEDGEMENTS}

The authors would like to express their thanks to professors and other staff members of OBG Department for permitting us to conduct the study. We would also like to express our gratitude to other staff members of department of pharmacology for their constant support.

Funding: No funding sources

Conflict of interest: None declared

Ethical approval: The study was done after obtaining clearance from the institutional ethical committee of Bidar institute of medical sciences Bidar, Karnataka, India

\section{REFERENCES}

1. Deborah E, McCarter, Spaulding MS. Medications in pregnancy and lactation. Amer J Maternal Child Nursing. 2005;30:10-7.

2. Duffull SB, David J. Woods Drugs in Pregnancy \& Lactation. In: Roger Walker and Clive Edwards. Clinical Pharmacy and Therapeutics. $3^{\text {rd }}$ edition. Churchill Livingstone Publisher; 2005. p. 739.

3. Banhidy F, Lowry RB, Czeizel AE. Risk and benefit of drug use in pregnancy. Int J ed Sci. 2005;2(3):1006.

4. Sachdeva P, Patel BG, Patel BK. Drug Use in Pregnancy; a point to ponder! Indian Journal of Pharmaceutical Sciences. 2009;71(1):1-7.

5. Dutta DK. Drugs used in Pregnancy \& its effects on baby and infants in alphabetical order. In: Dilip Kumar Dutta. Drugs in Pregnancy-How safe. 1stedition. India: Jaypee Brothers Medical Publishers. 2008:71.

6. World Health Organization. How to investigate drug use in health facilities, Selected drug use indicators, 
WHO/DAP/93.1. Geneva: World health Organization. 1993:10.

7. Frankos VH. FDA Perspectives on the use of teratology data for human risk. Assessment Fundam Appl Toxicol. 1985;5:615-25.

8. Pereira PLM, Nayak BS, Abdul-Lateef $\mathrm{H}$, Matmungal V, Mendes K, Persad S, et al. Drug utilization patterns in pregnant women: a case study at the Mount Hope Women's Hospital in Trinidad, West Indies. West Indian med J. 2010;59(5):561-6.
9. Malm H, Martikainen J, Kalukka T, Neuvonen PJ. Prescription of hazardous during pregnancy. Drug Saf. 2004;27:899-908.

10. Tisonova J, Magulova L, Goboova M, Wawruch M, Lassánová M, Bozeková L, et al. Consultation activity of two Slovak Centres for pharmacotherapy during pregnancy and lactation. Cas Lek Cesk. 2006;145(2):154-9.

Cite this article as: Savitha A, Sarita H, Gumma K. Drug pattern use during pregnancy: a prospective study at tertiary care teaching hospital. Int J Basic Clin Pharmacol 2016;5:192-5. 